\title{
Design of UWB Antenna for Human Body Communication
}

\author{
N. Sheshaprasad ${ }^{1}$, Aditi Rao ${ }^{2}$, Bhoomika R ${ }^{3}$, Eva D. Saglani ${ }^{4}$ \\ ${ }^{1}$ Associate Professor, Department of Electronics and Communications, B.N.M. \\ Institute of Technology, Bangalore, India. \\ ${ }^{2}$ B.E. Student, Department of Electronics and Communications, B.N.M. Institute of \\ Technology, Bangalore, India. \\ ${ }^{3}$ B.E. Student, Department of Electronics and Communications, B.N.M. Institute of \\ Technology, Bangalore, India. \\ ${ }^{4}$ B.E. Student, Department of Electronics and Communications, B.N.M. Institute of \\ Technology, Bangalore, India. \\ 1nsheshaprasad@bnmit.in, 2aditidrao1999@gmail.com, 33bhumigrv7@gmail.com, \\ 4eva.saglani@gmail.com
}

\begin{abstract}
A diamond-shaped patch antenna with slots for desirable return loss, gain, and bandwidth was designed to achieve the intended goal. ROGERS 5880 was chosen as the substrate material and the antenna was simulated using CST (Computer simulation Technology) software. The designed microstrip patch antenna has a bandwidth from 2.12 to $9.24 \mathrm{GHz}$. The proposed antenna was put on the human body and had a SAR value of $1.44 \mathrm{~W} / \mathrm{kg}$, which was determined to be within the acceptable limit of $1.6 \mathrm{~W} / \mathrm{kg}$. Hence, the antenna can be used for on-body communication which is not detrimental to the human body.
\end{abstract}

Keywords:Microstrip Patch, SAR, Ultra-Wideband, SAR, Reflection Co-efficient, $\mathrm{S}_{11}, \mathrm{CST}$.

\section{INTRODUCTION}

Due to the compact use of electronic embedded systems and hardware for a range of applications, such as medical sensor networks, emergency service personnel, and personal communications, on-body communication channels are becoming increasingly common. [1]. For on-body communication, the antennas must comply with certain requirements. The UWB technology has shown promising results since it can provide a broad BW with less power, and the usage of ultra-wideband communication for antenna design gives numerous benefits over the typical narrow band. UWB is feasible due to its higher attainable data rates and increased immunity to interference due to lower spectral power density. 
On the other hand, antenna designing for a UWB is very challenging as there are effects on the human body that needs to be considered. It should be kept in consideration of the gain and radiation pattern of the antenna on the human body for on-body communication. At communication frequency, the human body functions as a lossy dielectric, and EM radiation produced by mobiles may penetrate semisolid objects such as living tissues [2]. The antenna models must be built and tuned in such a way that the most important human tissues in the abdomen area may be modelled without causing any negative consequences. [3]. A voxel model of humans has been used which is developed in the CST software simulation to obtain the effect of antenna behaviour on the human skin. [4]. The microstrip line feed is a popular feeding approach because it is simple to construct, model, and match impedance. The varied shapes in which the patch is designed to give a variety of output parameters that allow the antenna to get better and efficient [5]. Since the antenna stands out for high frequencies the slotted patch antenna models serve for large bandwidth and therefore these types of antennas become an effective candidate [1].

In [4], the impedance bandwidth attained is 130 percent from 2.8 to $12 \mathrm{GHz}$, with an average gain of around $3.5 \mathrm{dBi}$. Because the antenna has a basic construction and is straightforward to make, it might be utilized for wireless communication. When modelled on the human body, the results demonstrate that this antenna does not suffer from significant frequency detuning due to free space resonance over the entire frequency range.

The effects of the human body on antenna gain are investigated and a mathematical relationship is put forward relating the fluctuation of distance from the body and the antenna gain. Using a half-wave dipole antenna, the analysis indicates that the gain values are linear up to a quarter wavelength, exponential up to one wavelength, and then linear again[6].

\section{ANTENNA DESIGN}

The microstrip antenna was designed for a resonant frequency of $8.9 \mathrm{GHz}$. The size of the antenna is $30 \times 20 \times 1.6 \mathrm{~mm}^{3}$ where the size of the patch is calculated using the formulae:

$$
L_{p}=W_{p}=\frac{c}{2 * f_{r} * \sqrt{\epsilon_{r}}}
$$

Apart from the patch calculation, the rest of the antenna parameters' dimensions were calculated using equations present in [7]. 
The side of the diamond-shaped antenna as shown in Fig.1, is calculated to be 11.36 and the thickness of the patch is taken as $0.035 \mathrm{~mm}$. Both the ground plane and the patch are made from copper. ROGERS 5880 having a dielectric constant of 2.2, was employed as the substrate because of its availability, high dielectric strength, moisture resistance, low cost, and ability to produce accurate results at higher frequencies.
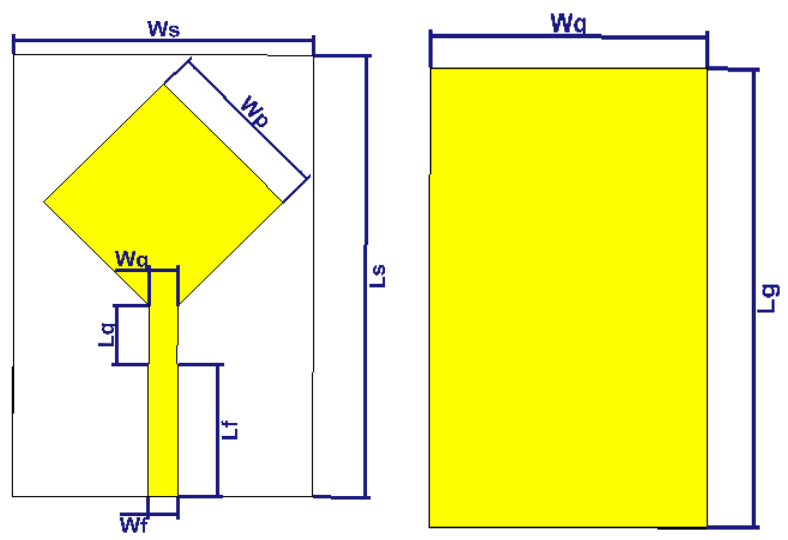

\section{Figure 1. Structure of the Base Antenna (Front and Back View)}

The diamond-shaped patch length was optimized to $11.31 \mathrm{~mm}$ to improve the bandwidth. Later, as illustrated in Fig.2, slots and slits were incorporated, as well as a reduction in the ground plane, to boost efficiency, enhance impedance matching, and expand the antenna's bandwidth. [10].
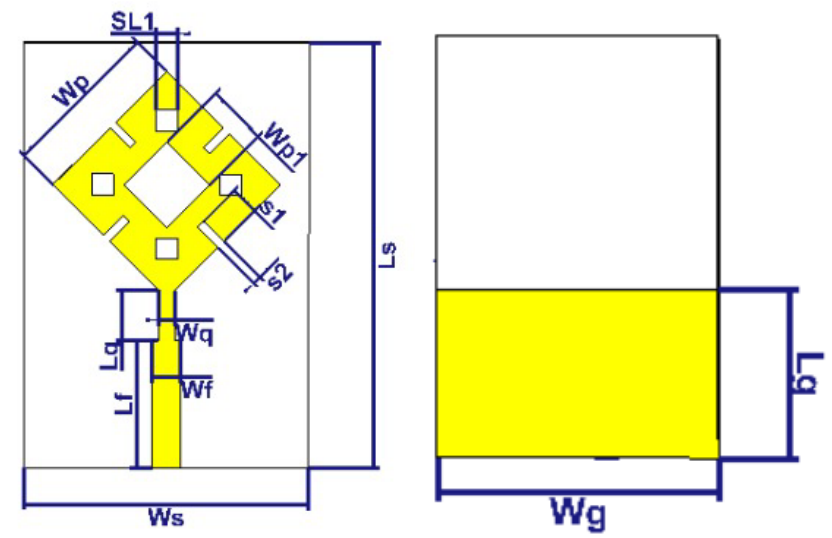

\section{Figure 2. Structure of the Proposed Antenna (Front and Back View)}

The base antenna has been modified by performing 3 different iterations - introducing a slot at the centre, introducing slits and slots on the sides of the antenna, and by reducing the ground plane to arrive at the proposed antenna design. The final antenna design parameters are as shown in Table I. 
Table I. Dimensions of the Proposed Antenna

\begin{tabular}{|c|c|}
\hline Name of the parameter & Value (in mm) \\
\hline Length of the substrate $\left(\mathrm{L}_{\mathrm{s}}\right)$ & 30 \\
\hline Length of the ground $\left(\mathrm{L}_{\mathrm{g}}\right)$ & 12 \\
\hline Width of the substrate $\left(\mathrm{W}_{\mathrm{s}}\right)$ & 20 \\
\hline Width of the ground $\left(\mathrm{W}_{\mathrm{g}}\right)$ & 20 \\
\hline Length of the feed $\left(\mathrm{L}_{\mathrm{g}}\right)$ & 9 \\
\hline Width and Length of the patch $\left(\mathrm{W}_{\mathrm{p}}=\mathrm{L}_{\mathrm{p}}\right)$ & 11.31 \\
\hline Height of the substrate $(\mathrm{h})$ & 1.6 \\
\hline The thickness of the patch $(\mathrm{t})$ & 0.035 \\
\hline Length of centre slot $\left(\mathrm{W}_{\mathrm{p} 1}\right)$ & 4.24 \\
\hline Length of slot (SL1) & 1.5 \\
\hline Length of the slit (s1) & 2 \\
\hline Width of the slit (s2) & 0.6 \\
\hline
\end{tabular}

\section{RESULT AND ANALYSIS}

The purpose of this section is to investigate the performance of the microstrip antenna in free space and on the human body. To achieve this, the antenna is simulated by using the CST Microwave Studio simulation tool. Fig.3 and Fig.4 illustrate the reflection coefficient and the directivity of the antenna in the free space.

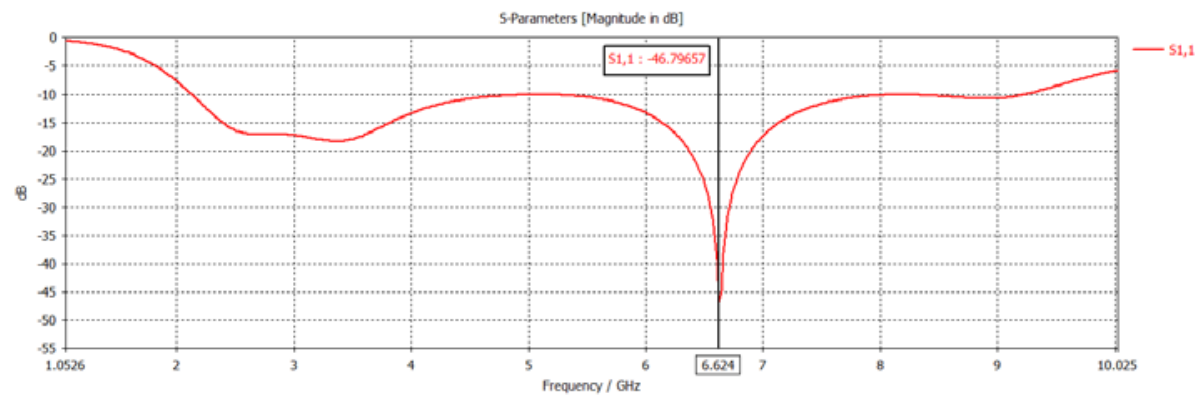

Figure 3. S11 of Antenna in Free Space

The antenna's return loss in free space is $-46.79657 \mathrm{~dB}$, and its directivity in free space is $2.638 \mathrm{dBi}$ at $6.624 \mathrm{GHz}$, as illustrated in Figs. 3 and 4. Since the antenna operates from 2.12 - $9.24 \mathrm{GHz}$, it can be used for ultra-wideband applications. 

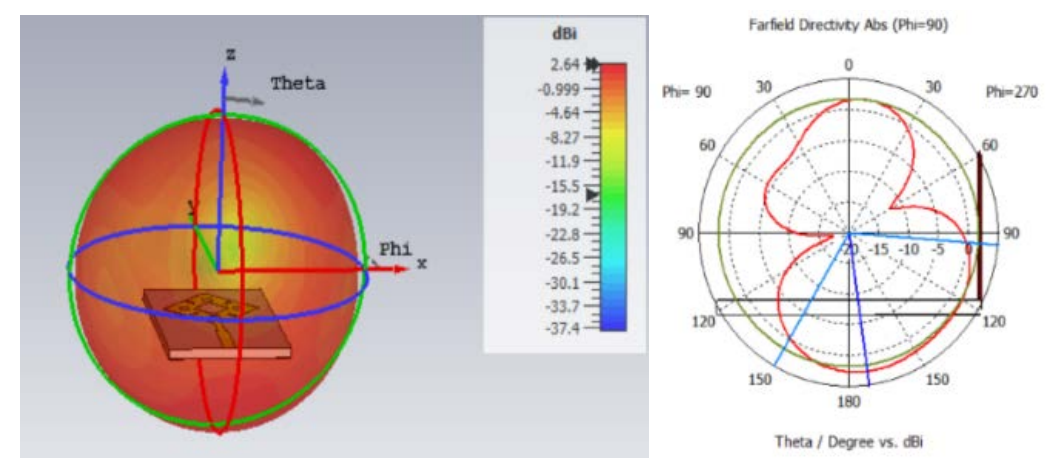

Figure 4. Directivity in Free Space at $6.624 \mathrm{GHz}$

Furthermore, the antenna is placed on the human model, Gustav, a 38-year-old male who is $176 \mathrm{~cm}$ and $69 \mathrm{~kg}$ as shown in Fig.5. The antenna is simulated in CST to obtain the antenna parameters and SAR value. Before the simulation, a layer called 'air' was constructed behind the ground plane and then the antenna was placed on the skin. The 'air' layer is important as the position of the antenna is critical due to the radiation effects on the human skin.

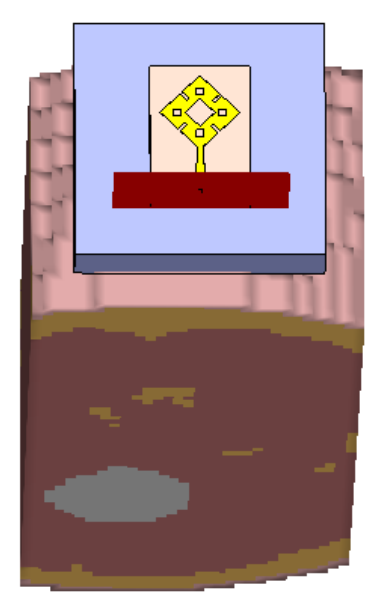

Figure 5. Antenna on the Human Body

Fig.6 and Fig.7 show the reflection co-efficient and the directivity of the antenna on the human body.

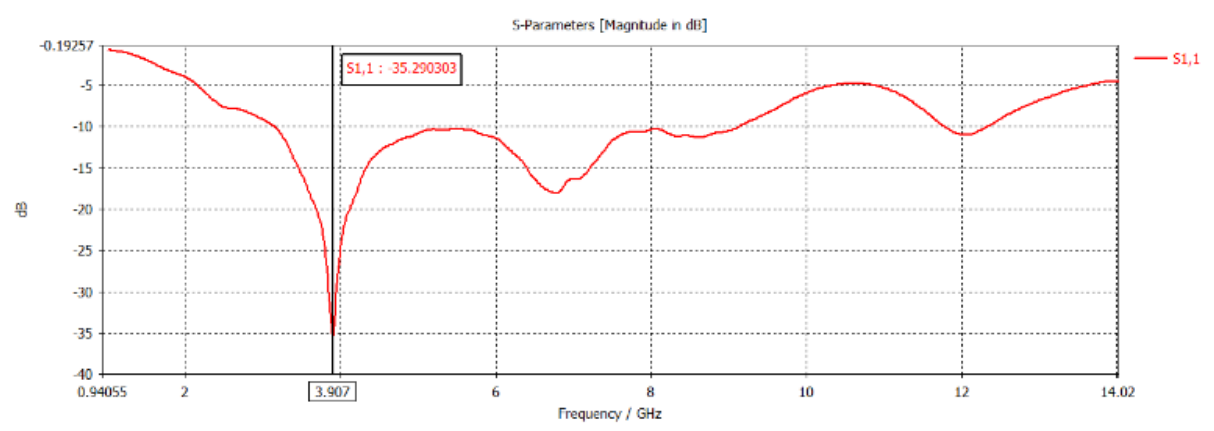

Figure 6. $S_{11}$ of Antenna on the Human Body 

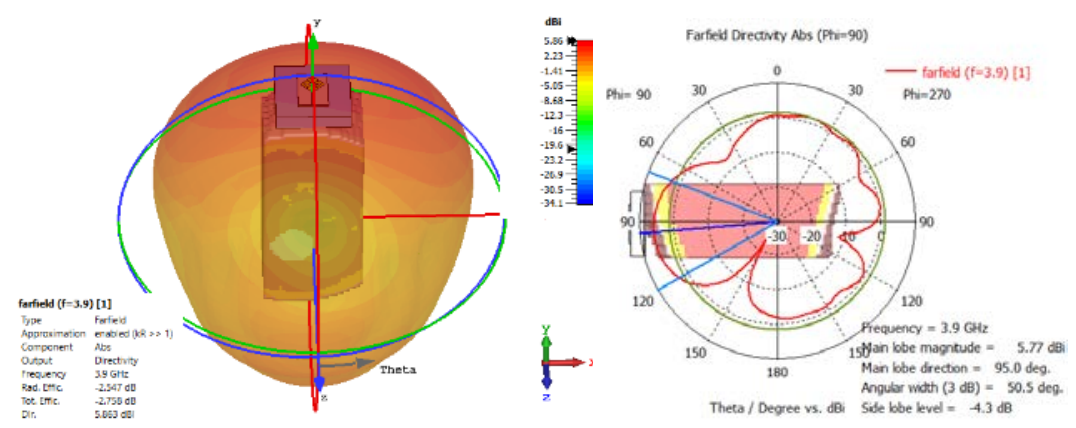

Figure 7. Directivity on the Human Body at $3.9 \mathrm{GHz}$

At a distance of $10 \mathrm{~mm}$ from the human body, the antenna was found to have a bandwidth of 3.152 - 9.132 GHz. As shown in Fig.6 and Fig.7, the return loss of the antenna on the human body is $-35.29 \mathrm{~dB}$ and the directivity of the antenna on the human body is 5.852 $\mathrm{dBi}$ at $3.888 \mathrm{GHz}$.

Specific Absorption Rate, also known as SAR, is a measurement of how much energy is absorbed per unit mass. The unit for SAR is $W / \mathrm{kg}$. The SAR is calculated for $1 \mathrm{~g}$ at different frequencies for different input powers regulated by IEEE C95.3 standard which are tabulated in Table II.

Table II. SAR of the Antenna at Different Frequencies

\begin{tabular}{|c|c|c|}
\hline $\begin{array}{c}\text { Input Power } \\
(\mathrm{W})\end{array}$ & Frequency $(\mathrm{GHz})$ & SAR Value $(\mathrm{W} / \mathrm{kg})$ \\
\hline \multirow{2}{*}{0.5} & 3.9 & 1.8511 \\
\hline & 5.8 & 1.838 \\
\hline \multirow{2}{*}{0.4} & 3.9 & 1.4809 \\
\hline & 5.8 & 1.4708 \\
\hline
\end{tabular}

The SAR value of the antenna was determined to be $1.4809 \mathrm{~W} / \mathrm{kg}$ for $1 \mathrm{~g}$ of tissue at the frequency of $3.9 \mathrm{GHz}$ with an input power of $0.4 \mathrm{~W}$, as illustrated in Fig.8. The SAR value is well within the Federal Communications Commission's (FCC) public exposure standard. As a result, the suggested ultra-wideband antenna can be utilised for on-body communication. 


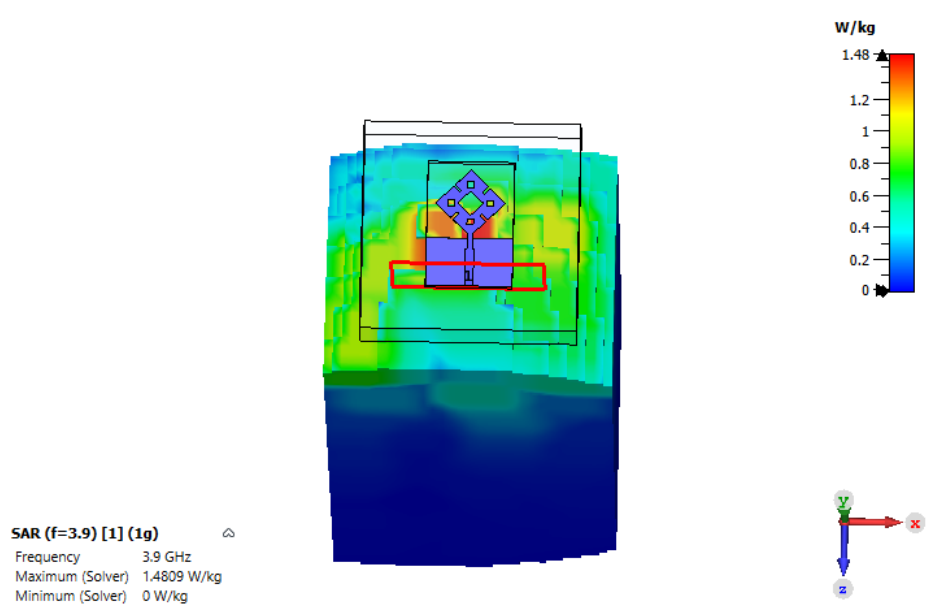

Figure 8: SAR of the Antenna for $1 \mathrm{~g}$ of Tissue

Furthermore, various parameters such as directivity, gain, VSWR, etc are measured and compared when the antenna is in free space and at a distance of $10 \mathrm{~mm}$ from the human body, which is tabulated in TABLE III.

Table III. Antenna Parameters when the Antenna is in Free Space and on the Human Body.

\begin{tabular}{|c|c|c|}
\hline Antenna Parameters & in Free Space & $\begin{array}{c}\text { At a distance of 10mm } \\
\text { Human Body }\end{array}$ \\
\hline Directivity (in dBi) & 2.638 & 5.863 \\
\hline Gain (in dB) & 1.392 & 3.36 \\
\hline Realized Gain (in dB) & 1.16 & 3.105 \\
\hline Reflection Co-efficient (in dB) & -46.7966 & -35.29 \\
\hline Peak Surface Current (in A/m) & 114.774 & 38.0966 \\
\hline VSWR & & 1.034 \\
\hline Total Efficiency (in dB) & -1.478 & -2.785 \\
\hline Radiation Efficiency (in dB) & -1.245 & -2.547 \\
& & \\
\hline
\end{tabular}

\section{CONCLUSION}

In this work, a diamond-shaped microstrip patch antenna in the UWB band was developed and simulated. Because of its compact size and ease of manufacture, this 
antenna is a preferable choice. Several simulated results in free space and on the human body were seen. In free space, the antenna was found to operate from $2.12 \mathrm{GHz}-9.24$ $\mathrm{GHz}$, with $7.12 \mathrm{GHz}$ bandwidth. On the human body, the antenna was found to operate from $3.152 \mathrm{GHz}-9.132 \mathrm{GHz}$, with $5.98 \mathrm{GHz}$ bandwidth. The SAR value of the antenna on the body was $1.44 \mathrm{~W} / \mathrm{kg}$ which is well within the limit of $1.6 \mathrm{~W} / \mathrm{kg}$. Lastly, from all the results, it was understood that the antenna was capable of on-body communication and produced less detrimental effects on the human body.

\section{ACKNOWLEDGEMENTS}

The authors would like to express their gratitude to Visvesvaraya Technological University, Belgaum, India, and the department of ECE at BNM Institute of Technology, Bengaluru, India, for their invaluable assistance during this project.

\section{REFERENCES}

[1] Gareth A, Conway, and William G. Scanlon, "Antennas for Over-Body Surface Communication at 2.45 GHz”, IEEE Transactions on Antennas and Propagation, VOL. 57, NO. 4, APRIL 2009.

[2] Navdeep Kaur, Rajni, "Design and Simulation of Microstrip Patch Antenna for On-Body Communication using Different Feeding Techniques”, UACEE International Journal of Advancements in Electronics and Electrical Engineering - IJAEE, Volume 20132, Issue-3, September.

[3] Enrique Miralles, Carlos Andreu, Marta Cabedo-Fabrés,MiguelFerrando-Bataller, Jose F. Monserrat,"UWB On-Body Slotted Patch Antennas for In-Body Communications", $11^{\text {th }}$ European Conference on Antennas and Propagation (EUCAP), 2017.

[4] Amin Darvazehban and TaranehRezaee, "Ultra-Wideband Microstrip Antenna for Body Centric Communications”, ACES JOURNAL, Vol. 33, No. 3, March 2018.

[5] SourabhBisht, Shweta Saini, Dr.Ved Prakash, Bhaskar Nautiyal, "Study the Various Feeding Techniques of Microstrip Antenna Using Design and Simulation Using CST Microwave Studio”, International Journal of Emerging Technology and Advanced Engineering, Volume 4, Issue 9, September2014.

[6] ShakibRahat Chowdhury, Khaleda Ali, "Effects of Human Body on Antenna Performance: A Quantitative Study", 19th International Conference on Computer and Information Technology, December2016.

[7] LitonChandra Paul, Nahid Sultan, "Design, Simulation and Performance Analysis of a Line Feed Rectangular Micro-Strip Patch Antenna”, International Journal of Engineering Sciences \& Emerging Technologies, Volume 4, Issue 2, February 2013, ISSN: 2231-6804.

[8] UditRaithatha, S. Sreenath Kashyap, "Microstrip Patch Antenna Parameters, Feeding Techniques \& Shapes of the Patch - A Survey”, International Journal of Scientific \& Engineering Research, Volume 6, Issue 4, April-2015, ISSN 2229-5518.

[9] HunsGregoiySchunt, "Introduction to ultra-wideband antennas”, IEEE Conference on Ultra-Wideband System and Technologies,2003.

[10] MinhTuan Nguyen, Byoungchul Kim, Hosung Choo, and Ikmo Park, "Effects of Ground Plane Size on a Square Microstrip Patch Antenna Designed on a Low-Permittivity Substrate with an Air Gap", 2010 International Workshop on Antenna Technology (iWAT), March2010. 